\title{
Brain Anatomy and Anatomical Distribution of Major Brain Tumors
}

Brain anatomy \& anatomical distribution of major brain tumors

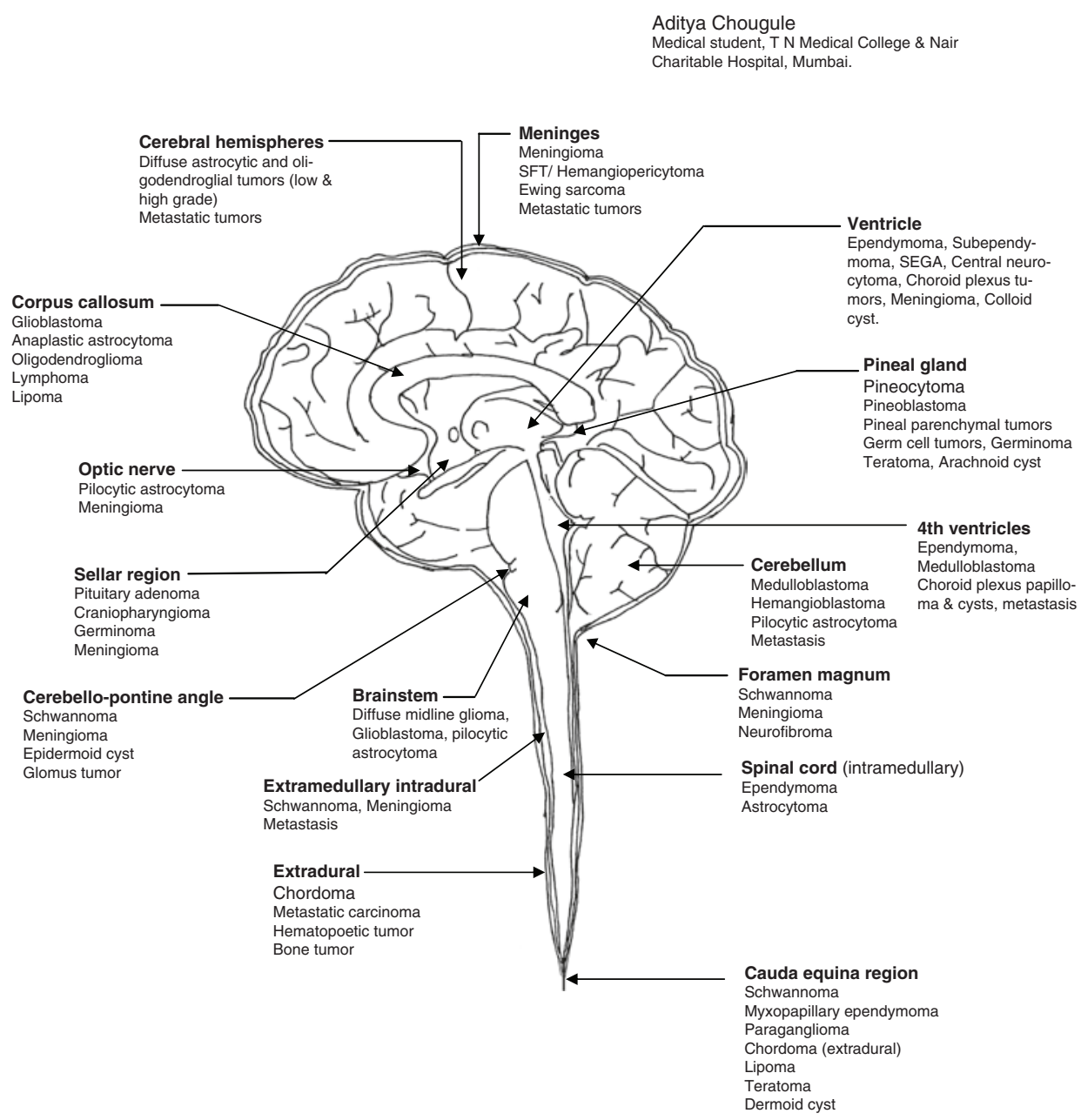

Sagittal view of normal brain and spinal cord with major tumors and their locations. 